Changes in functioning outcomes as a predictor of the course of depression:

a 12-month longitudinal study.

Carlos G. Forero ${ }^{\mathrm{a}, \mathrm{b}, \mathrm{c} *}$, Elena Olariu ${ }^{\mathrm{b}, \mathrm{c}}$, Pilar Álvarez ${ }^{\mathrm{d}}$, José-Ignacio Castro-Rodriguez ${ }^{\mathrm{b}, \mathrm{cd}}$, Maria Jesús Blasco $^{\mathrm{a}, \mathrm{b}, \mathrm{c}}$, Gemma Vilagut ${ }^{\mathrm{a}, \mathrm{b}, \mathrm{c}}$,Jordi Alonso ${ }^{\mathrm{a}, \mathrm{b}, \mathrm{c}}$ on behalf of INSAyD Investigators

a Centro de Investigación Biomédica en Red en Epidemiología y Salud Pública (CIBERESP), Madrid b Health Services Research Unit, hospital del Mar Medical Research Institute (IMIM), Barcelona c Department of Experimental and Health Sciences, Universitat Pompeu Fabra (UPF), Barcelona d Institute of Neuropsychiatry and Addictions (INAD), Parc de Salut Mar, Barcelona

\title{
Acknowledgments
}

This work was supported by grants from the Spanish Ministry of Health, Instituto de Salud Carlos III, Fondo Europeo de Desarrollo Regional (FEDER) PI10/00530, PI13/00506, and PI16/00165, and by Departament d'Innovació, Universitats i Empresa (2014 SGR748; 2009 SGR1095. Gemma Vilagut was supported by Fondo de Investigación Sanitaria, Instituto de Salud Carlos III ECA07/059.

*Correspondent author: Carlos G Forero

Health Services Research Unit, IMIM (Institut Hospital del Mar d'Investigacions Mèdiques), Carrer del Doctor Aiguader, 88, Edifici PRBB, 08003, Barcelona, Spain. Phone: (+34) 933160 760; Fax: (+34) 933 160 797. E-mail: cgarcia@imim.es

INSAyD Investigators: Jordi Alonso, Carlos G Forero, Gemma Vilagut, Pilar Álvarez, José-Ignacio Castro-Rodriguez, Luis Miguel Martín-López, Lina Abellanas, Carrie Garnier, Maria Rosa Mas, Elena Pérez-Gallo, Marta Reinoso, Gabriela Barbaglia, Miquel A. Fullana, Alberto Maydeu, Anna Brown 


\section{Change in functioning outcomes as a predictor of the course of depression:}

\section{a 12-month longitudinal study.}

\section{ABSTRACT}

Purpose: Functioning is a necessary diagnostic criterion for depression, and thus routinely assessed in depressive patients. While it is highly informative of disorder severity, its change has not been tested for prognostic purposes. Our study aimed to analyze to what extent early functioning changes predict depression in the mid-term.

Methods: Longitudinal study (four occasions: baseline, 1-, 3-, and 12-months) of 243 patients with depressive symptomatology at three different services (primary care, outpatients, and hospital). Functioning was assessed on the first three occasions using the Global Assessment of Functioning, (GAF), the WHODAS-2.0, and a self-reported functioning (SRF) rating scale. Growth mixture modeling of initial assessments served to estimate individual person-change parameters of each outcome. Persongrowth parameters were used as predictors of Major Depressive Episode at 12 months in a logistic regression model, adjusted by sex, age, healthcare level, and depression clinical status at third month. Predictive accuracy of all measures was assessed with area under the receiver operating curve (AUC). Results: Of the 179 patients who completed all assessments, $58 \%$ had an active depression episode at baseline and $20 \%$ at 12 months (64\% non-recoveries and 36\% new onsets). Individual trends of change in functioning significantly predicted patient depression status a year later $\left(\mathrm{AUC}_{\mathrm{WHODAS}}=0.76\right.$; $\left.\mathrm{AUC}_{\mathrm{GAF}}=0.92 ; \mathrm{AUC}_{\mathrm{SRF}}=0.93\right)$.

Conclusions: Longitudinal modeling of functioning was highly predictive of patients' clinical status after one year. Although clinical and patient-reported assessment had high prognostic value, the use of very simple patient-reported outcome measures could improve case management outside specialized psychiatric services.

Keywords: Affective disorders, Early intervention, Questionnaire, Functional Disability, WHODAS. 
Change in functioning outcomes as a predictor of the course of depression: a 12-month longitudinal study.

\section{INTRODUCTION}

As the most prevalent mental health problem, depression is among the most significant challenges for health services. Depression affects between 10 -and $20 \%$ of the general population during the lifetime [1,2], and increases prevalence up to a $30 \%$ [3] in primary care samples where cases are mostly encountered [4]. Precisely in this setting time constraints and patient schedules put to a test case detection and patient monitoring [5]. With such limitations, practical methods for monitoring psychiatric patients are needed for improving patient management [6].

In-depth psychiatric assessment is unfeasible in primary care. Since the introduction of the multiaxial system in DSM-III [7], functioning is a central outcome in psychiatry. Functioning is the ability to perform in daily activities without interference derived from illness, or the lack of disability due to a health status $[8,9]$, is a central construct in psychiatry, it varies with the progress of clinical symptoms [6, 10-12]. However, a limited amount of research has been devoted to the value of functioning for monitoring and prognosis in psychiatric patients [11, 13]. This fact can be the result of both analytical approaches that has been used in longitudinal studies of functioning in depression with the practical difficulties for its assessment. 
Most longitudinal investigations on functioning have used methods that address average group change, such as repeated methods ANOVA [14]. These methods do not allow to control withinindividual effects and score autocorrelations when estimating change over time [15]. Consequently, they are not adequate to model individual patterns of change. There are few applications of longitudinal models, for modeling individual functioning trends psychiatric patients. Such modeling approach is frequent in physical and mental comorbidity studies. Longitudinal studies on functional limitations in relationship to mental health are common in studies about mental health and chronic disease, conspicuously in aging studies [16-18]. However, it is far less common in psychiatry patients, where functioning is mostly treated as an indicator associated with symptoms or treatment course.

It is worth to remark that undemanding methods for appraising functioning in mental health patients have been difficult to obtain so that their use health services have been somewhat disregarded. Arguably, the traditional gold standard of functioning in mental health, the DSMIV Global Assessment of Functioning (GAF) [16], has been concentrated in specialized services. GAF assessment is conducted and reported by professionals and requires specialized training to evaluate patient's health status: the GAF is a prototypical example of the so-called Clinical Reported Outcomes (ClinRO; [21]). As the GAF requires substantial psychiatric training, inter-rater reliability is dependent on clinical experience [22, 23], a barrier for professionals lacking expertise in psychiatric assessment [11]. Also, the GAF scores depend both on functioning disability and symptom severity, which deviates from guidelines of the International Classification of Functioning, that separate functioning from health status [25]. To correct this misalignment, the DSM-5 [26, 27] propose World Health Organization disability Schedule 2.0 (WHODAS 2.0) [9], a direct report coming from patients of their own health condition without interpretation of the patient's response by a clinician or anyone else (i.e. a Patient Reported Outcome, PRO) [21]. The WHODAS has excellent psychometric properties [28] and is sensitive to clinical depression [29]. More recently, some research has proposed propose simpler one-item numerical rating scales of functioning, similar to those used in pain 
assessment [30]. PRO scales have shown good reliability and concurrence with experts' ratings [31], as well as sensitivity to the course of symptoms [32, 33]. Given its straightforwardness, PROs methodology might be more suitable for rapid assessment of functioning in nonpsychiatric services.

The importance of functioning in assessing depression, and defining its makes worth studying its usefulness for prognosis. Evidence in this regard can be helpful for providing tools for assessment and monitoring outside specialized psychiatric services. In this study, we aimed to study whether the use of early longitudinal functioning information in cases under monitoring for mood symptomatology is useful for to make predictions of the course depression. As a second objective, we tried to compare the adequate method for functioning monitoring by comparing the predictive ability of ClinRo and PRO functioning assessment.

\section{METHODS}

\subsection{Design and sample selection}

The sample was part of the Inventory of Depression and Anxiety Symptoms (INSAyD), $[32,33])$, project for studying tools for diagnosis and communication among healthcare professionals. INSAyD was an observational, prospective study (baseline, 1-, 3- and 12-month assessments) in a cohort of patients seeking help for affective distress recruited in three care levels: primary care, outpatient mental health centers, and acute psychiatric inpatient hospitals. Patients from different care levels were included to increase the range of severity close to the threshold of pathology, from subthreshold to severe. Care levels served as an initial proxy of initial patient severity that allowed, ultimately, maximizing the variety of course evolution and over time in patients. 
Inclusion criteria were a) adults older than 18 years old with demands for active affective symptomatology; b) willing to participate in the study. Patients with psychotic symptoms, bipolar disorder, symptoms attributed to organic or substance origin, cognitive impairment (Mini-Mental State Examination $<24$ points [34]), life expectancy under six months or language problems were excluded. Participation was offered to 327 patients that met inclusion criteria, and 243 consented to participate ( $74 \%$ response rate).

\subsection{Procedures}

Patients were invited to participate by health professionals and then informed by a certified trained psychologist of the nature and methods of the study. After signing informed consent, patients were assessed in-person and scheduled for follow-up after baseline the evaluation. After a year, a trained clinician conducted a phone interview as a final assessment. Patients were considered dropouts if they missed any follow-up appointment and could not be reached by phone after five attempts. Details on the study are provided elsewhere [33]

\subsection{Clinical Diagnosis}

Psychopathology at baseline was assessed using MINI-International Neuropsychiatric Interview 5.0 (MINI) [35]. Given time constraints, we included only the sections Major Depression Episode (MDE), and dysthymia, bipolar disorder, panic disorder, generalized anxiety disorder (GAD) and suicide risk. Depression was tracked at baseline and follow-ups using the Patient Health Questionnaire 9 (PHQ-9) [36]. The PHQ9is interpretable according to DSM criteria using the following diagnostic algorithm [37] (at least five items answered as "more than half the days" or "nearly every day", and suicidal ideation whenever the response is different from “never"). The PHQ-9 has excellent reliability, validity and diagnostic accuracy and over 90\% diagnostic accuracy when compared to the MINI [38].

\subsection{Clinical and Patient Reported Outcomes Assessment}

ClinRO assessment of functioning was conducted using DSM-IV axis V criteria with the Spanish version of the Global Assessment of Functioning [39], scoring from 0 to 100 from 
total disability to superior functioning. The GAF uses 10-point tabulation guidelines for decision; at each level, the decision considers the worst of either symptom severity or functioning, and the GAF examinations stop at the 10-point interval where both constructs meet the criteria.

Sociodemographic variables were gathered during the clinical interview: age (in years), gender, nationality, education level (primary, secondary, and higher college education), employment status (employed, unemployed or other situations) civil status (married or living with partner, divorced, or separated, and widowed. Clinical assessment included information regarding comorbid physical conditions extracted from clinical record [40]. Given the low frequency of individual conditions, comorbidities were treated as counts of concurrent conditions in a patient.

We used two methods of PRO assessment. Firstly, the 12-item Spanish version of the World Health Organization Disability Assessment Scale 2.0 (WHODAS 2.0) [41], with scores into a 0 (highest) to 100 (lower) functioning (i.e., higher disability). The second PRO was selfreported functioning (SRF) using a one-item numerical rating scale. The SRF asks the patient: "On a scale from 0 (lowest) to 100, (highest) how you would currently rate your overall level of functioning?" This procedure has shown good discriminant and criterion validity for detecting $\operatorname{MDE}[32$ 30, 31]

All three methods are transformed into a 0 to 100 scale so that different scaling was not a source of heterogeneity.

\subsection{Statistical Analysis}

We computed descriptive statistics od the sample and score change during the followups. Instrument test-retest reliability in a group of stable patients during the first month was computed using two-way random effects intraclass correlation coefficient for absolute agreement in multiple measurements. 
Analyses followed a two-tier modeling process, depicted in figure 1 using path diagrammatic conventions. As a first step (continuous lines in figure 1), we fitted a growth mixture model (GMM) for estimation of person-evolution parameters. In a second step (dashed lines in figure 1), parameters predicted 12-month depression in a logistic regression model.

\section{INSERT FIGURE 1 ABOUT HERE}

\subsubsection{Growth mixture modeling of functioning changes}

We modeled individual early functioning trends (baseline to $3^{\text {rd }}$ follow-up), using GMM, a case-centered modeling that allows estimating intra-individual and inter-individual variability in longitudinal assessments [42]. GMM describe person evolution with two parameters (see fig. 1): intercept $(i)$, which represent starting values, and slope $(s)$, the rate of change over time. Parameters can be understood evolution-scores of functioning, describing the rate of change conditional on initial functioning. The model included correlation between $i$ and $s$ to control association between initial functioning and its evolution, thus accountinng for effects such as regression towards the mean (i.e., more severe cases are prone to steeper recoveries).

As not all patients departed from initial levels of severity, the model tested for sample inter-subject heterogeneity inferring the presence of homogeneous latent subgroups $c$ in the sample. Starting with a single-cluster model (i.e., all group shares an overall trajectory), then adding clusters for each successive model (i.e., specific groups have different trajectories). The final number of subgroups $c$ was decided using the following criteria: more than $10 \%$ subjects in the smallest cluster; not-significant Lo-Mendell-Rubin likelihood ratio test (Adjusted LMR_LRT ) between $\mathrm{c}$ and $c+1$ clusters, and lowest value in Bayesian Information Criteria (BIC) [43]. Estimation was conducted using full information maximum likelihood (FIML). This 
approach has been to have adequate power for detecting classes and significant trends in samples as small as $150-200$ cases $[15,43,44]$

Slopes were scaled in months to indicate the rate of monthly change in functioning. As only three-time points were available, and to avoid model overfitting, we did not attempt to model curvilinear trends over time.

\subsubsection{Prediction of 12-month status using person-parameters of functioning change}

To determine the predictive ability of individual early functioning trajectories on patient depression status at 12 months, individual parameters $i_{n}$ and $s_{k}$ were introduced as predictors of MDE 12-month status in binary logistic regression models. Predictive models were estimated using a nested approach. Six models were estimated: three methods of assessment (GAF, WHODAS, and SRF), with and without adjustment by disorder status at third month. Functioning measures were treated as continuous predictors of MDE status as a dichotomous outcome (active/inactive). Models were adjusted for age, number of comorbid chronic conditions, and presence of mental comorbidity (as assessed by MINI), health setting (primary care, outpatient, and hospital), and gender (see figure 1). Parameters significance (using Wald's test), and odds ratios (ORs), were obtained. Fit was assessed using Nagelkerke's Pseudo Rsquared and Hosmer-Lemeshow fit test using eight groups.

We tested predictive accuracy of the logistic model using Area Under the Receiver Operating Curve (AUC) using 12-month MDE status as status variable. AUCs and classification accuracy statistics of model-expected probabilities at Youden's Index: sensitivity, specificity, Positive and Negative predictive values, and positive and negative Likelihood Ratios. Predictive analyses used a 10-fold cross-validation sample to avoid overfitting. For comparability, we inverted the direction of WHODAS (which, opposite to the GAF and SRF, reflects worse functioning in higher scores). We expected that ORs would be below 1, indicating that increasing functioning lowers the likelihood of disorder. 


\subsection{Missing data handling.}

Growth models and LR were estimated using FIML, thus accounting for missing data across time [45]. For ROC and predictive accuracy analyses, we applied multiple imputation using the fully conditional specification method via Markov Chain Montecarlo (FCS-MCMC), with five imputed datasets for pooled analyses [46] with 2000 randomly chosen starting values. Both in FIML and FCS-MCMC, values were imputed for missingness according to the presence of at least one point of longitudinal information, so that 8 cases with all missing data during the follow-up were dropped from the analysis. Sensitivity analyses showed that excluding individuals with missing data resulted in similar cluster structure estimates.

Analyses were conducted using MPlus 7.2 and SPSS 20.0.

\section{RESULTS}

In total, 233 of the 243 patients completed the baseline assessment, and 179 of them completed the 12 -month follow up (74\% response rate). Psychiatric outpatients had a smaller proportion of drop-outs (25\%) than primary care and hospitalized patients (about $40 \%$ each). Despite this differential attrition, additional analyses did not show that loses-to-follow up by center were significantly associated with differences in predictor or outcome variables. The average age was 49.1 years old $(\mathrm{SD}=14.8)$, and $69 \%$ were women; $58 \%$ cases fulfilled DSM-5 symptom criteria for active MDE symptomatology at baseline, $56 \%$ of them with comorbid mental disorders (generalized anxiety, panic or dysthymia). The average number of physical conditions was $1.13(\mathrm{SD}=1)$. Table 1 shows sample descriptives at baseline.

TABLE 1 ABOUT HERE 
As seen in Table 2, MDE prevalence significantly decayed over time $F_{1,139}=30.36$, $p=<0.00$ ), from $57.9 \%$ to $21 \%$. From the $20 \%$ patients with MDE at 12 months, $64 \%(\mathrm{n}=23)$ showed no recovery during the first three months, while the remaining $36 \%(n=14)$ were new onsets during the follow-up. Self-reported measures showed a significant trend toward improvement during the first three assessments $\left(\operatorname{GAF} F_{1,162}=22.73 \mathrm{p}=<0.00\right.$; WHODAS $F_{1,142}=24.1, \mathrm{p}<0.00 ;$ SRF $\left.F_{1,161}=12.80, \mathrm{p}<0.00\right)$. Instruments' test-retest reliability were 0.52 , $0.83,0.57$ for the GAF, WHODAS, and SRF, respectively, with lower reliability levels in single-item measures.

TABLE 2 ABOUT HERE

Table 3 shows GMM model selection and parameters. For all measures, the $c=1$ class solution was preferred over solutions with more classes. The 2-class solution had either very low frequencies in the smallest cluster $(\mathrm{GAF}=2.8 \%$; WHODAS $=49.2 \%$; $\mathrm{SRF}=3.2 \%)$ or a nonsignificant LMR_LRT over the 1 clusters solutions (GAF 17.97 p=0.07; WHODAS=23.78 $=0.05 ; \mathrm{SRF}=21.45, p=0.03)$. The $\mathrm{c}=1$ class solution had also lower $\mathrm{BIC}$ values $(\mathrm{GAF}=4819 \mathrm{vs}$. 4807 ; WHODAS $=3948$ vs. $3,937 \mathrm{SRF}=5750$ vs.5730). Table 3 shows good fit of the 1 -cluster model according to chi-square, and standardized root mean squared residual, indicating the homogeneous variability of the functioning change. As there was no sign of substantial heterogeneity in patient change profiles, the sample was treated as a homogenous group.

The GAF showed the highest standardized intercept value (5.51) and WHODAS the lowest deviation from average (3.0). Slopes showed change towards functioning recovery in all measures, $($ GAF 1.97 points/month; WHODAS $=-1.14$ points $/$ month; $\mathrm{SRF}=2.43$ points/month). Notice that, given WHODAS scaling, higher values reflect greater disability, its slope was negative. Standardized slopes of the GAF showed the fastest change rate (0.57), 
followed by WHODAS (-0.47), and SRF (0.36). Intercept and slopes were negatively correlated $\left(r_{\text {isGAF }}=-0.47 ; r_{\text {isWHODAS }}=-.32 ; r_{\text {isSRF }}=-.45\right.$ in $\left.\mathrm{SRF}\right)$, indicating steepest that functioning recovery was steeper in cases lower functioning levels at baseline, a sign of regression towards the mean. The final GMM model explained a large number of indicator variances across occasions, with a minimum of $51 \%\left(1^{\text {st }}-\right.$ month SRF $)$ and a maximum of $87 \%\left(3^{\text {rd }}-\right.$ month SRF $)$.

\section{TABLE 3 ABOUT HERE}

Table 4 shows that MDE status at the $3^{\text {rd }}$ month significantly increased the likelihood of active MDE symptomatology at 12 months $(\mathrm{OR}=11.19)$. However, when functioning was considered, 3rd-month MDE became non-significant (GAF and SRF) or was substantially (WHODAS OR=5.84). For all measures, a higher intercept value (indicative of better functioning at baseline) indicated a reduced likelihood of 12-month MDE. The GAF was highly predictive of 12-month MDE symptoms $(\mathrm{OR}=0.73)$, followed by $\mathrm{SRF}(\mathrm{OR}=2.09)$. Models indicated that 1-point differences in the slope parameter, (indicative of steeper patient improvement) predicted lower probabilities of active MDE at 12 months. Changes in selfreported measures were likely to predict 12 -month symptomatology (GAF OR=0.14; SRF $=0.40)$, but slope was not significant in the case of the WHODAS $(\mathrm{OR}=1.16, p=0.62)$.

\section{TABLE 4 ABOUT HERE}

Figure 2 compares the predictive ability of each measure using the ROC curves in the cross-validation, with an without considering the MDE status at the $3^{\text {rd }}$ month. 
AUCs indicated that person functioning trends, as assessed with the three methods, were accurate predictors of MDE symptom status at 12 months. Active MDE at the third-month associated with MDE 12-month status $\left(\mathrm{AUC}_{\mathrm{MDE3m}}=0.72\right)$. Functioning trends predicted 12month symptoms, $\left(\mathrm{AUC}_{\mathrm{WHODAS}}=0.76, \mathrm{AUC}_{\mathrm{GAF}}=0.92 ; \mathrm{AUC}_{\mathrm{SRF}}=0.93\right)$. Noticeably, including 3month symptom status in the trajectory model significantly improved WHODAS predictive ability $\left(\mathrm{AUC}_{\mathrm{WHODAS}}=0.79\right)$, but not GAF and SRF predictive abilities. All models yielded high sensitivities at Youden's Index, $(\mathrm{GAF}=0.93$; WHODAS=0.89; $\mathrm{SRF}=0.84)$. However, specificity was significantly lower for WHODAS $(0.56,95 \% \mathrm{CI}=0.50-0.63)$ than for $\operatorname{GAF}(0.83$, $95 \% \mathrm{CI}=0.78-0.88)$ and $\mathrm{SRF}$ assessments $(0.95,95 \% \mathrm{CI}=0.92-0.98)$. Overall, the $\mathrm{SRF}$ was the most accurate instrument, with Likelihood ratio positive 15.82 and negative 0.17 ; While the WHODAS performed the worst in this regard $(\mathrm{LR}+=1.95, \mathrm{LR}-=0.24)$.

When stratified by MDE status at the third month, GAF and SRF trends parameters predicted quite well whether MDE positive cases would remain active at 12-month assessment $\left(\mathrm{AUC}_{\mathrm{GAF}}=0.94 \mathrm{SE}=0.02 ; \mathrm{AUC}_{\mathrm{SRF}}=0.94 \mathrm{SE}=0.02\right)$, outperforming WHODAS $\left(\mathrm{AUC}_{\mathrm{WHODAS}}=0.85, \mathrm{SE}=0.03\right)$. Moreover, $\mathrm{GAF}$ and $\mathrm{SRF}$ trend detected new onsets in negative cases at the $3^{\text {rd }}$ month $\left(\mathrm{AUC}_{\mathrm{GAF}}=0.80 \mathrm{SE}=0.4 ; \mathrm{AUC}_{\mathrm{SRF}}=0.83 \mathrm{SE}=0.03\right)$. WHODAS was not able to predict new onsets over chance $\left(\mathrm{AUC}_{\mathrm{WHODAS}}=0.59, \mathrm{SE}=0.26\right)$.

\section{DISCUSSION}

Assessment of functioning disability is compulsory for diagnosing depression, and a key outcome for defining remission. In this study, we investigated whether initial changes of ClinRO and PRO measures of functioning (WHODAS2.0 and SRF) predicted patient 
depression status after a year, using GMM, a method specifically devised to capture individual information in change trends.

Our study indicates that tracking functioning disability is useful for predicting the course of clinical depression. In isolation from other mental health information, ClinRO and PRO functioning measures achieved predictions of 12-month clinical status with AUCs over 0.75. Functioning evolution trends predicted remissions, but also new onsets in patients with initial affective distress but without an active MDE diagnosis. Adding information about patient's MDE status at the 3rd month did not increase prediction accuracy: conditional on patients' initial severity, functioning disability trends contained sufficient information for prognosis.

Results must be interpreted in the light of their limitations. First, the sample is composed of patients seeking health care for mental symptomatology, all of them underwent at least minimally adequate treatment [49]. Therefore, our results cannot be generalized to non-treated cases. Also, the fact that all cases had some level of symptomatology, impeded us to provide diagnostic cut-offs. However, recruitment in this study was representative of the clinical course of patients who demand attention for affective distress. Secondly, it is important to highlight that the INSAyD cohort was devised to maximize initial patient severity so that different courses of illness could be found during the follow-up. Our results do not imply that depression has a homogeneous course. On the contrary, correlated intercepts $i$ and slopes $s$ assumed that individual course is not independent of severity. Thus, the proper way to interpret model results is that conditional on initial severity levels of functioning, functioning trends in our sample was homogeneous. Thirdly, the use of only three follow-ups impeded modeling non-linearity in recovery, which is initially steeper; this would result in underestimation of the explained variance of change. Also, notice that the 12-month follow up was not included in the GMM model, as it was concurrent with MDE status at 12-month. Even though including 12-month functioning would allow describing quadratic trends of recovery, the clinical and functioning status at 12-monthh would be simultaneous, precluding the predictive hypothesis that was the objective of this work. The usefulness of concurrent measures of functioning for screening 
MDE was treated elsewhere [32]. Finally, we did not consider individual symptoms as predictors of depression course. We controlled the symptom effects by controlling for $3^{\text {rd }}$ month MDE status, given that evidence indicates that individual symptom trends are predictive of depression course [50].

At the same time, our study design has some strengths. We measured and compared functioning disability with two gold standard instruments: the traditional clinical GAF proposed in the DSM-IV and the more recent WHODAS proposed in the DSM-5. To our knowledge, this is the first comparison of these instruments in a longitudinal design with patients seeking health care: a case that confronts two assessment approaches (ClinRO vs. PROs) in a naturalistic situation regarding the patient demands. Also, the 12-month period permits avoiding the lag between symptom and functioning recovery [13].

The model provides evidence that, once patients are followed for emotional distress, the evolution of functioning during early patient monitoring allows predicting their symptoms after 12 months. Our result adds to previous evidence about the usefulness of functioning assessment in MDE and the interrelatedness of subjective functioning and affective distress [29, 51]. Functioning disability has been pointed as an endpoint of patient treatment $[6,11]$, and also as a method for guiding treatment $[5,13,52]$. However, beyond PROs and ClinROs as outcomes, this study found that quantitatively accrued information on patient's self-perceived changes serves for prognosis. In a previous study, Moos et al. [14] found no evidence of the usefulness of the GAF for this objective. However, their analytic approach focused on average change and did not extract information on within-individual measures. In our study, a growth model, an explicitly longitudinal technique, models the rate of individual change, something that is not possible with ANOVA-like techniques. Just for comparison, we devised a logistic regression model including functioning scores (not person trends) at baseline, first and 3rd and MDE at third month. In such model, only third-month MDE status was a significant predictor, with AUCs were between 0.74 (for WHODAS) and 0.78 (for GAF). The lower predictive ability is a 
consequence of a well-known property that motivates longitudinal modeling [15]: the contribution of within-individual information to a within-subjects repeated measurement. These results hint to a promising line of research in PROs predictors of health outcomes. The application of longitudinal models allows going from patient's snapshots to patient's dynamics, which results in much higher predictive ability.

An unexpected result was that individual trends of GAF and SRF outperformed WHODAS, which was less sensitive to patient changes during the follow-up for prognosis. The WHODAS physical disability contents may be adding noise when it comes to assessing mental health functioning. Physical limitations only influence depression functioning in the most severe cases [29], so these contents might render the WHODAS unspecific for mild or moderate depressions. A second difference is that the WHODAS is an instrument with norm-based scores. Despite using just one indicator to decide, the GAF and SRF tasks have nuances that may lead to higher responsiveness to clinical change.

We consider that the different predictive ability of the methods is a relevant result- Not all methods are equally feasible in all health settings: self-reported methods (SRF and WHODAS) are easy to apply and require no training, rendering them adequate in non-specialized services. On the contrary, the clinical method (GAF) require extensive training and experience in psychiatric assessment. The GAF mixes the assessment of pure functioning impairment with an expert assessment of symptom severity. While this is a construct validity issue that has been criticized [53], the overlap between functioning and symptoms can be of advantage when predicting clinical course. As for the SRF, patients are likely assessing the rate at which they are coming close to their functioning standards, the satisfaction with the rhythm of recovery and, ultimately, with treatment results. There is evidence that patients' impressions of their status use historical information about themselves as a reference for providing scores [54, 55].

\section{Conclusions}


Using patient-reported health status for targeting interventions in specific patient populations is an increasingly recommended practice [56]. PRO measures might be suitable for mental health management $[57,58]$. A highly predictive monitoring would allow clinicians to anticipate patient aggravation and chronification, which might lead to more personalized interventions.

Taking advantage of longitudinal of PRO information is promising in this regard, and aligns with other evidence pointing at the potential of PROs for mental health assessment in settings with pressing demands $[52,60]$. It is no not likely that PROs provide reliable measures in other mental health disorders, especially when they course with low awareness, confusional states or impaired understanding, such as in psychosis or substance use. 


\section{Compliance with ethical standards}

Conflict of interest: The authors declare that they have no conflict of interest.

Ethical approval: All procedures performed in this study were in accordance with the ethical standards of the institutional and national research committees and with the 1964 Helsinki declaration and its later amendments or comparable ethical standards. The protocol, information letters, questionnaires, and the informed consent forms of the study were approved by the Clinical Research Institutional Review Board (IRB) at Parc de Salut Mar, Barcelona in Spain. As a non-intervention, there was no expected adverse event or side effect for participants.

Informed consent: Informed consent was obtained from all individual participants included in the study

\section{References}

1. Alonso, J., Lépine, J.-P., \& ESEMeD/MHEDEA 2000 Scientific Committee. (2007). Overview of key data from the European Study of the Epidemiology of Mental Disorders (ESEMeD). The Journal of clinical psychiatry, 68 Suppl 2, 3-9.

2. Kessler, R. C. (2012). The costs of depression. The Psychiatric clinics of North America, 35(1), 1-14. doi:10.1016/j.psc.2011.11.005

3. Serrano-Blanco, A., Palao, D. J., Luciano, J. V, Pinto-Meza, A., Luján, L., Fernández, A., ... Haro, J. M. (2010). Prevalence of mental disorders in primary care: results from the diagnosis and treatment of mental disorders in primary care study (DASMAP). Social Psychiatry and Psychiatric Epidemiology, 45(2), 201-210. doi:10.1007/s00127-009-0056-y

4. Wang, P. S., Aguilar-Gaxiola, S., Alonso, J., Angermeyer, M. C., Borges, G., Bromet, E. J., ... Wells, J. E. (2007). Use of mental health services for anxiety, mood, and substance disorders in 17 countries in the WHO world mental health surveys. The Lancet, 370(9590), 841-850. doi:10.1016/S0140-6736(07)61414-7

5. Gilbody, S. M. (2003). Improving the detection and management of depression in primary care. Quality and Safety in Health Care, 12(2), 149-155. doi:10.1136/qhc.12.2.149

6. Zimmerman, M., McGlinchey, J. B., Posternak, M. A., Friedman, M., Attiullah, N., \& Boerescu, D. (2006). How Should Remission From Depression Be Defined? The Depressed Patient's Perspective. American Journal of Psychiatry, 163(1), 148-150. doi:10.1176/appi.ajp.163.1.148

7. American Psychiatric Association. (1980). Diagnostic and statistical manual of mental disorders (3rd Edition). Diagnostic and Statistical Manual of Mental Disorders 3rd Edition. Washington DC. doi:10.1016/B978-1-4377-2242-0.00016-X

8. Mittal, V. A., \& Walker, E. F. (2011). Diagnostic and Statistical Manual of Mental Disorders. Psychiatry Research, 189(1), 158-159. doi:10.1016/j.psychres.2011.06.006

9. Üstün, T., Kostanjsek, N., Chatterji, S., \& Rehm, J. (2010). Measuring health and disability: manual for WHO Disability Assessment Schedule (WHODAS 2.0). 
10. Buist-Bouwman, M. (2004). Functioning after a major depressive episode: complete or incomplete recovery? Journal of Affective Disorders, 82(3), 363-371.

doi:10.1016/j.jad.2004.02.007

11. Zimmerman, M., McGlinchey, J. B., Posternak, M. A., Friedman, M., Boerescu, D., \& Attiullah, N. (2008). Remission in depressed outpatients: More than just symptom resolution? Journal of Psychiatric Research, 42(10), 797-801. doi:10.1016/j.jpsychires.2007.09.004

12. Vázquez-Barquero, J. L., Vázquez Bourgón, E., Herrera Castanedo, S., Saiz, J., Uriarte, M., Morales, F., ... Ustün, T. B. (2011). [Spanish version of the new World Health Organization Disability Assessment Schedule II (WHO-DAS-II): initial phase of development and pilot study. Cantabria disability work group]. Actas espanolas de psiquiatria, 28(2), 77-87.

13. McKnight, P. E., \& Kashdan, T. B. (2009). The importance of functional impairment to mental health outcomes: A case for reassessing our goals in depression treatment research. Clinical Psychology Review, 29(3), 243-259. doi:10.1016/j.cpr.2009.01.005

14. Moos, R. H., McCoy, L., \& Moos, B. S. (2000). Global assessment of functioning (GAF) ratings: Determinants and role as predictors of one-year treatment outcomes. Journal of Clinical Psychology, 56(4), 449-461. doi:10.1002/(SICI)1097-4679(200004)56:4<449::AIDJCLP1>3.0.CO;2-8

15. Curran, P. J., Obeidat, K., \& Losardo, D. (2010). Twelve Frequently Asked Questions About Growth Curve Modeling. Journal of Cognition and Development, 11(2), 121-136. doi:10.1080/15248371003699969

16. Hajek, A., Brettschneider, C., Eisele, M., Lühmann, D., Mamone, S., Wiese, B., ... König, H.-H. (2017). Disentangling the complex relation of disability and depressive symptoms in old age findings of a multicenter prospective cohort study in Germany. International Psychogeriatrics, 29(6), 885-895. doi:10.1017/S1041610216002507

17. Hybels, C. F., Pieper, C. F., \& Blazer, D. G. (2009). The complex relationship between depressive symptoms and functional limitations in community-dwelling older adults: the impact of subthreshold depression. Psychological Medicine, 39(10), 1677. doi: $10.1017 / \mathrm{S} 0033291709005650$

18. Mendes de Leon, C. F., \& Rajan, K. B. (2014). Psychosocial Influences in Onset and Progression of Late Life Disability. The Journals of Gerontology Series B: Psychological Sciences and Social Sciences, 69(2), 287-302. doi:10.1093/geronb/gbt130

19. Sherwood, A., Blumenthal, J. A., Hinderliter, A. L., Koch, G. G., Adams, K. F., Dupree, C. S., ... O’Connor, C. M. (2011). Worsening Depressive Symptoms Are Associated With Adverse Clinical Outcomes in Patients With Heart Failure. Journal of the American College of Cardiology, 57(4), 418-423. doi:10.1016/j.jacc.2010.09.031

20. Asuzu, C. C., Walker, R. J., Williams, J. S., \& Egede, L. E. (2017). Pathways for the relationship between diabetes distress, depression, fatalism and glycemic control in adults with type 2 diabetes. Journal of Diabetes and its Complications, 31(1), 169-174. doi:10.1016/j.jdiacomp.2016.09.013

21. Powers, J. H., Patrick, D. L., Walton, M. K., Marquis, P., Cano, S., Hobart, J., ... Burke, L. B. (2017). Clinician-Reported Outcome Assessments of Treatment Benefit: Report of the ISPOR Clinical Outcome Assessment Emerging Good Practices Task Force. Value in Health, 20(1), 2 14. doi:10.1016/j.jval.2016.11.005

22. Vatnaland, T., Vatnaland, J., Friis, S., \& Opjordsmoen, S. (2007). Are GAF scores reliable in routine clinical use? Acta Psychiatrica Scandinavica, 115(4), 326-330. doi:10.1111/j.16000447.2006.00925.x

23. S[[ouml]]derberg, P., Tungstr[[ouml]]m, S., \& Armelius, B. [[Aring]]ke. (2005). Special Section on the GAF: Reliability of Global Assessment of Functioning Ratings Made by Clinical 
Psychiatric Staff. Psychiatric Services, 56(4), 434-438. doi:10.1176/appi.ps.56.4.434

24. Sherbourne, C. D., Sullivan, G., Craske, M. G., Roy-Byrne, P., Golinelli, D., Rose, R. D., ... Stein, M. B. (2010). Functioning and disability levels in primary care out-patients with one or more anxiety disorders. Psychological Medicine, 40(12), 2059-2068. doi: $10.1017 /$ S0033291710000176

25. Cieza, A., Brockow, T., Ewert, T., Amman, E., Kollerits, B., Chatterji, S., ... Stucki, G. (2002). Linking Health-Status Measurements to the International Classification of Functioning, Disability and Health. Journal of Rehabilitation Medicine, 34(5), 205-210. doi:10.1080/165019702760279189

26. American Psychiatric Association. (2013). DSM 5. American Journal of Psychiatry. doi:10.1176/appi.books.9780890425596.744053

27. Regier, D. A., Kuhl, E. A., \& Kupfer, D. J. (2013). The DSM-5: Classification and criteria changes. World Psychiatry, 12(2), 92-98. doi:10.1002/wps.20050

28. Federici, S., Meloni, F., \& Presti, A. L. (2009). International literature review on WHODAS II (World Health Organization Disability Assessment Schedule II). Life Span and Disability, 12(1), $83-110$.

29. Luciano, J. V., Ayuso-Mateos, J. L., Fernandez, A., Aguado, J., Serrano-Blanco, A., Roca, M., \& Haro, J. M. (2010). Utility of the twelve-item World Health Organization Disability Assessment Schedule II (WHO-DAS II) for discriminating depression "caseness" and severity in Spanish primary care patients. Quality of Life Research, 19(1), 97-101. doi:10.1007/s11136-009-9566-z

30. Bodlund, O., Kullgren, G., Ekselius, L., Lindström, E., \& von Knorring, L. (1994). Axis V-Global Assessment of Functioning Scale. Evaluation of a self-report version. Acta psychiatrica Scandinavica, 90(5), 342-7.

31. Ramirez, A., Ekselius, L., \& Ramklint, M. (2008). Axis V - Global Assessment of Functioning Scale (GAF), further evaluation of the self-report version. European Psychiatry, 23(8), 575-579. doi:10.1016/j.eurpsy.2008.05.001

32. Olariu, E., Forero, C. G., Álvarez, P., Castro-Rodriguez, J.-I., Blasco, M., \& Alonso, J. (2015). Asking patients about their general level of functioning: Is IT worth IT for common mental disorders? Psychiatry Research, 229(3), 791-800. doi:10.1016/j.psychres.2015.07.088

33. Olariu, E., Castro-Rodriguez, J.-I., Álvarez, P., Garnier, C., Reinoso, M., Martín-López, L. M., ... Forero, C. G. (2015). Validation of clinical symptom IRT scores for diagnosis and severity assessment of common mental disorders. Quality of Life Research, 24(4), 979-992. doi:10.1007/s11136-014-0814-5

34. Folstein, M. F., Folstein, S. E., \& McHugh, P. R. (1975). "Mini-mental state.” Journal of Psychiatric Research, 12(3), 189-198. doi:10.1016/0022-3956(75)90026-6

35. Sheehan, D. V., Lecrubier, Y., Sheehan, K. H., Amorim, P., Janavs, J., Weiller, E., ... Dunbar, G. C. (1998). The MINI-International Neuropsychiatric Interview (M.I.N.I.): The Development and Validation of a Structured Diagnostic Psychiatric Interview for DSM-IV and ICD-10. The Journal of Clinical Psychiatry, 59(suppl 20), 22-33.

36. Kroenke, K., Spitzer, R. L., \& Williams, J. B. (2001). The PHQ-9: validity of a brief depression severity measure. Journal of general internal medicine, 16(9), 606-13.

37. Fitzpatrick, R., Gibbons, E., \& Mackintosh, A. (2009). An overview of patient-reported outcome measures for people with anxiety and depression 2009. Patient-reported Outcome Measurement Group Department of Public Health University of Oxford.

38. Pettersson, A., Boström, K. B., Gustavsson, P., \& Ekselius, L. (2015). Which instruments to support diagnosis of depression have sufficient accuracy? A systematic review. Nordic Journal of 
Psychiatry, 69(7), 497-508. doi:10.3109/08039488.2015.1008568

39. First, M. (2001). Manual Diagnóstico y Estadístico de los Trastornos Mentales DSM-IV TR. Barcelona: Masson.

40. Centers for Disease Control and Prevention, \& National Center for Health Statistics. (2013). ICD - ICD-9-CM - International Classification of Diseases, Ninth Revision, Clinical Modification. Classification of Diseases, Functioning, and Disability, 2008, 1-2.

41. Vázquez-Barquero, J. L., Vázquez Bourgón, E., Herrera Castanedo, S., Saiz, J., Uriarte, M., Morales, F., ... Ustün, T. B. (2000). [Spanish version of the new World Health Organization Disability Assessment Schedule II (WHO-DAS-II): initial phase of development and pilot study. Cantabria disability work group]. Actas Españolas de Psiquiatría, 28(2), 77-87.

42. Curran, P. J., Bauer, D. J., \& Willoughby, M. T. (2004). Testing Main Effects and Interactions in Latent Curve Analysis. Psychological Methods, 9(2), 220-237. doi:10.1037/1082-989X.9.2.220

43. Nylund, K. L., Asparouhov, T., \& Muthén, B. O. (2007). Deciding on the Number of Classes in Latent Class Analysis and Growth Mixture Modeling: A Monte Carlo Simulation Study. Structural Equation Modeling: A Multidisciplinary Journal, 14(4), 535-569. doi:10.1080/10705510701575396

44. Dziak, J. J., Lanza, S. T., \& Tan, X. (2014). Effect Size, Statistical Power, and Sample Size Requirements for the Bootstrap Likelihood Ratio Test in Latent Class Analysis. Structural Equation Modeling: A Multidisciplinary Journal, 21(4), 534-552. doi:10.1080/10705511.2014.919819

45. Larsen, R. (2011). Missing Data Imputation versus Full Information Maximum Likelihood with Second-Level Dependencies. Structural Equation Modeling: A Multidisciplinary Journal, 18(4), 649-662.

46. van Buuren, S. (2007). Multiple imputation of discrete and continuous data by fully conditional specification. Statistical Methods in Medical Research, 16(3), 219-242.

doi: $10.1177 / 0962280206074463$

47. Pincus, H. A., Pechura, C. M., Elinson, L., \& Pettit, A. R. (2001). Depression in primary care: linking clinical and systems strategies. General hospital psychiatry, 23(6), 311-8. doi:10.1016/S0163-8343(01)00165-7

48. Moos, R. H., Nichol, A. C., \& Moos, B. S. (2002). Global Assessment of Functioning Ratings and the Allocation and Outcomes of Mental Health Services. Psychiatric Services, 53(6), 730737. doi:10.1176/appi.ps.53.6.730

49. Castro-Rodríguez, J. I., Olariu, E., Garnier-Lacueva, C., Martín-López, L. M., Pérez-Solà, V., Alonso, J., \& Forero, C. G. (2015). Diagnostic accuracy and adequacy of treatment of depressive and anxiety disorders: A comparison of primary care and specialized care patients. Journal of Affective Disorders, 172, 462-471. doi:10.1016/j.jad.2014.10.020

50. Wardenaar, K. J., Giltay, E. J., van Veen, T., Zitman, F. G., \& Penninx, B. W. J. H. (2012). Symptom dimensions as predictors of the two-year course of depressive and anxiety disorders. Journal of Affective Disorders, 136(3), 1198-1203. doi:10.1016/j.jad.2011.11.037

51. Tiersky, L. A., DeLuca, J., Hill, N., Dhar, S. K., Johnson, S. K., Lange, G., ... Natelson, B. H. (2001). Longitudinal Assessment of Neuropsychological Functioning, Psychiatric Status, Functional Disability and Employment Status in Chronic Fatigue Syndrome. Applied Neuropsychology, 8(1), 41-50. doi:10.1207/S15324826AN0801_6

52. Fleury, M.-J., Ngui, A., Bamvita, J.-M., Grenier, G., \& Caron, J. (2014). Predictors of Healthcare Service Utilization for Mental Health Reasons. International Journal of Environmental Research and Public Health, 11(12), 10559-10586. doi:10.3390/ijerph111010559 
53. Álvarez, A. S. (2012). The Application of the International Classification of Functioning, Disability, and Health in Psychiatry. American Journal of Physical Medicine \& Rehabilitation, 91, S69-S73. doi:10.1097/PHM.0b013e31823d4f1c

54. Geisser, M. E., Clauw, D. J., Strand, V., Gendreau, M. R., Palmer, R., \& Williams, D. A. (2010). Contributions of change in clinical status parameters to Patient Global Impression of Change (PGIC) scores among persons with fibromyalgia treated with milnacipran. Pain, 149(2), 373-378. doi:10.1016/j.pain.2010.02.043

55. Ramirez, A., Ekselius, L., \& Ramklint, M. (2008). Axis V - Global Assessment of Functioning Scale (GAF), further evaluation of the self-report version. European Psychiatry, 23, 575-579. doi:10.1016/j.eurpsy.2008.05.001

56. Bradley, S. M., Rumsfeld, J. S., \& Ho, P. M. (2016). Incorporating Health Status in Routine Care to Improve Health Care Value. JAMA, 316(5), 487. doi:10.1001/jama.2016.6495

57. Olariu, E., Forero, C. G., Álvarez, P., Castro-Rodriguez, J.-I., Blasco, M., \& Alonso, J. (2015). Asking patients about their general level of functioning: Is IT worth IT for common mental disorders? Psychiatry Research, 229(3), 791-800. doi:10.1016/j.psychres.2015.07.088

58. Sheeran, T., \& Zimmerman, M. (2002). Case identification of depression with self-report questionnaires. Psychiatry research, 109(1), 51-9.

59. Zimmerman, M., Ruggero, C. J., Chelminski, I., Young, D., Posternak, M. A., Friedman, M., ... Attiullah, N. (2006). Developing Brief Scales for Use in Clinical Practice: The Reliability and Validity of Single-Item Self-Report Measures of Depression Symptom Severity, Psychosocial Impairment Due to Depression, and Quality of Life. The Journal of Clinical Psychiatry, 67(10), 1536-1541. doi:10.4088/JCP.v67n1007

60. Alson, A. R., Robinson, D. M., Ivanova, D., Azer, J., Moreno, M., Turk, M. L., ... Blackman, K. S. (2016). Depression in primary care. The International Journal of Psychiatry in Medicine, 51(2), 182-200. doi:10.1177/0091217416636580 
Table 1. Sociodemographic and clinical characteristics of the study sample

\begin{tabular}{|c|c|c|c|c|c|}
\hline \multirow[b]{2}{*}{ Sociodemographic variables } & \multirow[b]{2}{*}{$\mathbf{N}(\%)$} & \multicolumn{4}{|c|}{ Active mental disorders } \\
\hline & & $\begin{array}{l}\text { No active } \\
\text { mental } \\
\text { disorder } \\
\mathrm{N}(\%)\end{array}$ & $\begin{array}{l}\text { Pure MDE } \\
\text { N }(\%)\end{array}$ & $\begin{array}{c}\text { MDE } \\
+ \text { comorbid }^{\mathrm{b}} \\
\mathrm{N}(\%)\end{array}$ & $\begin{array}{c}\text { Other } \\
\text { Disorders } \\
\mathrm{N}(\%)\end{array}$ \\
\hline Total & $233(100)$ & $75(32.2)$ & $79(33.9)$ & $56(24.0)$ & $23(9.9)$ \\
\hline Age, $M(S D)$ & $49.1(14.8)$ & $50.5(16.1)$ & $51.1(13.3)$ & $46.1(15.2)$ & $45(13.2)$ \\
\hline \multicolumn{6}{|l|}{ Gender } \\
\hline Male & $72(30.9)$ & $26(34.7)$ & $23(29.1)$ & $15(26.8)$ & $8(34.8)$ \\
\hline Female & $161(69.1)$ & $49(65.3)$ & $56(70.9)$ & $41(73.2)$ & $15(65.2)$ \\
\hline \multicolumn{6}{|l|}{ Nationality } \\
\hline Spanish & $212(91.4)$ & $69(92.0)$ & $72(91.1)$ & $49(89.1)$ & $22(95.6)$ \\
\hline Not Spanish & $20(8.6)$ & $6(8.0)$ & $7(8.9)$ & $6(10.9)$ & $1(4.4)$ \\
\hline \multicolumn{6}{|l|}{ Education level } \\
\hline Less than Primary \& Primary & $92(39.5)$ & $32(42.7)$ & $30(38.0)$ & $25(44.6)$ & $5(21.7)$ \\
\hline Secondary & $97(41.6)$ & $25(33.3)$ & $38(48.1)$ & $21(37.5)$ & $13(56.6)$ \\
\hline Higher & $44(18.9)$ & $18(24.0)$ & $11(13.9)$ & $10(17.9)$ & $5(21.7)$ \\
\hline \multicolumn{6}{|l|}{ Employment status } \\
\hline employed & $106(45.5)$ & $34(45.3)$ & $30(38.0)$ & $27(48.2)$ & $15(65.2)$ \\
\hline unemployed & $118(50.6)$ & $40(53.3)$ & $43(54.4)$ & $27(48.2)$ & $8(34.8)$ \\
\hline Other (retired, students) & $9(3.9)$ & $1(1.3)$ & $6(7.6)$ & $2(3.6)$ & $0(0)$ \\
\hline \multicolumn{6}{|l|}{ Civil status } \\
\hline Never married & $61(26.2)$ & $18(24)$ & $22(27.9)$ & $12(21.4)$ & $9(39.1)$ \\
\hline Married or living with a partner & $132(56.6)$ & $42(56)$ & $47(59.5)$ & $33(58.9)$ & $10(43.5)$ \\
\hline Divorced or separated & $30(12.9)$ & $12(16)$ & $8(10.1)$ & $7(12.5)$ & $3(13)$ \\
\hline Widowed & $10(4.3)$ & $3(4)$ & $2(2.5)$ & $4(7.2)$ & $1(4.4)$ \\
\hline \multicolumn{6}{|l|}{ Setting } \\
\hline Primary Care & $91(39.0)$ & $31(41.3)$ & $15(19.0)$ & $30(53.6)$ & $15(65.2)$ \\
\hline Outpatient mental health centers & $122(52.4)$ & $42(56)$ & $47(59.5)$ & $25(44.6)$ & $8(34.8)$ \\
\hline Hospital & $20(8.6)$ & $2(2.7)$ & $17(21.5)$ & $1(1.8)$ & 0 \\
\hline $\begin{array}{l}\text { Patients with physical } \\
\text { comorbidities }\end{array}$ & $175(77 \%)$ & $55(73 \%)$ & $59(74 \%)$ & $47(83)$ & $20(86)$ \\
\hline \multicolumn{6}{|l|}{ Number Physical conditions } \\
\hline \multicolumn{6}{|l|}{ Mental disorders } \\
\hline $\mathrm{MDE}^{\mathrm{b}}$ & $135(57.9)$ & $0(0)$ & $79(100)$ & $56(100)$ & $0(0)$ \\
\hline Dysthymia & $10(4.3)$ & $0(0)$ & $0(0)$ & $0(0)$ & $10(13.3)$ \\
\hline (Hypo)mania & $12(5.2)$ & $0(0)$ & $5(6.3)$ & $6(10.7)$ & $1(1.3)$ \\
\hline Panic & $33(14.2)$ & $0(0)$ & $10(12.6)$ & $18(29.9)$ & $5(21.7)$ \\
\hline $\mathrm{GAD}^{\mathrm{b}}$ & $79(33.9)$ & $0(0)$ & $0(0)$ & $56(100)$ & $23(100)$ \\
\hline
\end{tabular}

${ }^{a}$ Major Depressive Episode; ${ }^{b}$ Generalized Anxiety Disorder, Panic Disorder, Dysthimia, Hypomania

$M$ mean, $S D$ standard deviation, IQR: Interquatile Range. 
Table 2. Descriptives of functioning measures at baseline and follow-ups.

\begin{tabular}{|c|c|c|c|c|c|c|c|c|c|c|c|c|}
\hline & \multicolumn{12}{|c|}{ Assessment } \\
\hline & \multicolumn{3}{|c|}{$\begin{array}{l}\text { Baseline } \\
(N=233)\end{array}$} & \multicolumn{3}{|c|}{$\begin{array}{l}\text { 1-month } \\
(N=190)\end{array}$} & \multicolumn{3}{|c|}{$\begin{array}{l}\text { 3-month } \\
(N=174)\end{array}$} & \multicolumn{3}{|c|}{$\begin{array}{l}\text { 12-month } \\
(N=179)\end{array}$} \\
\hline & Mean [\%] & $\begin{array}{c}\mathrm{SD} \\
{[\mathrm{SE}]}\end{array}$ & $\begin{array}{c}\mathrm{Min} / \mathrm{Med} / \mathrm{M} \\
\mathrm{ax}\end{array}$ & $\begin{array}{c}\text { Mean } \\
{[\%]}\end{array}$ & $\begin{array}{l}\mathrm{SD} \\
{[\mathrm{SE}]}\end{array}$ & $\begin{array}{c}\text { Min/Med/ } \\
\text { Max }\end{array}$ & $\begin{array}{c}\text { Mean } \\
{[\%]}\end{array}$ & $\begin{array}{l}\mathrm{SD} \\
{[\mathrm{SE}]}\end{array}$ & $\begin{array}{l}\text { Min/Med/ } \\
\text { Max }\end{array}$ & $\begin{array}{c}\text { Mean } \\
{[\%]}\end{array}$ & $\begin{array}{l}\mathrm{SD} \\
{[\mathrm{SE}]}\end{array}$ & $\begin{array}{c}\text { Min/Med/ } \\
\text { Max }\end{array}$ \\
\hline Active MDE cases & {$[57.9 \%]$} & {$[0.03]$} & -- & $32 \%$ & {$[0.03]$} & -- & $26 \%$ & 0.03 & -- & $21 \%$ & {$[0.03]$} & -- \\
\hline GAF & 66.38 & [0.99] & $10 / 70 / 100$ & 70.52 & {$[1.07]$} & $7 / 70 / 100$ & 72.52 & {$[1.08]$} & $30 / 75 / 100$ & -- & -- & -- \\
\hline WHODAS & 28.63 & {$[0.75]$} & $12 / 17 / 56$ & 26.68 & {$[0.83]$} & $12 / 24 / 57$ & 24.82 & {$[0.84]$} & $12 / 23 / 52$ & 20.37 & 0.65 & $12 / 17 / 48$ \\
\hline SRF & 50.08 & {$[1.52]$} & $0 / 50 / 100$ & 56.12 & {$[1.60]$} & $0 / 60 / 100$ & 58.20 & [1.09] & $30 / 75 / 100$ & 59.34 & 1.58 & $7 / 60 / 100$ \\
\hline
\end{tabular}


Table 3. Model fit and estimated parameters of GM model

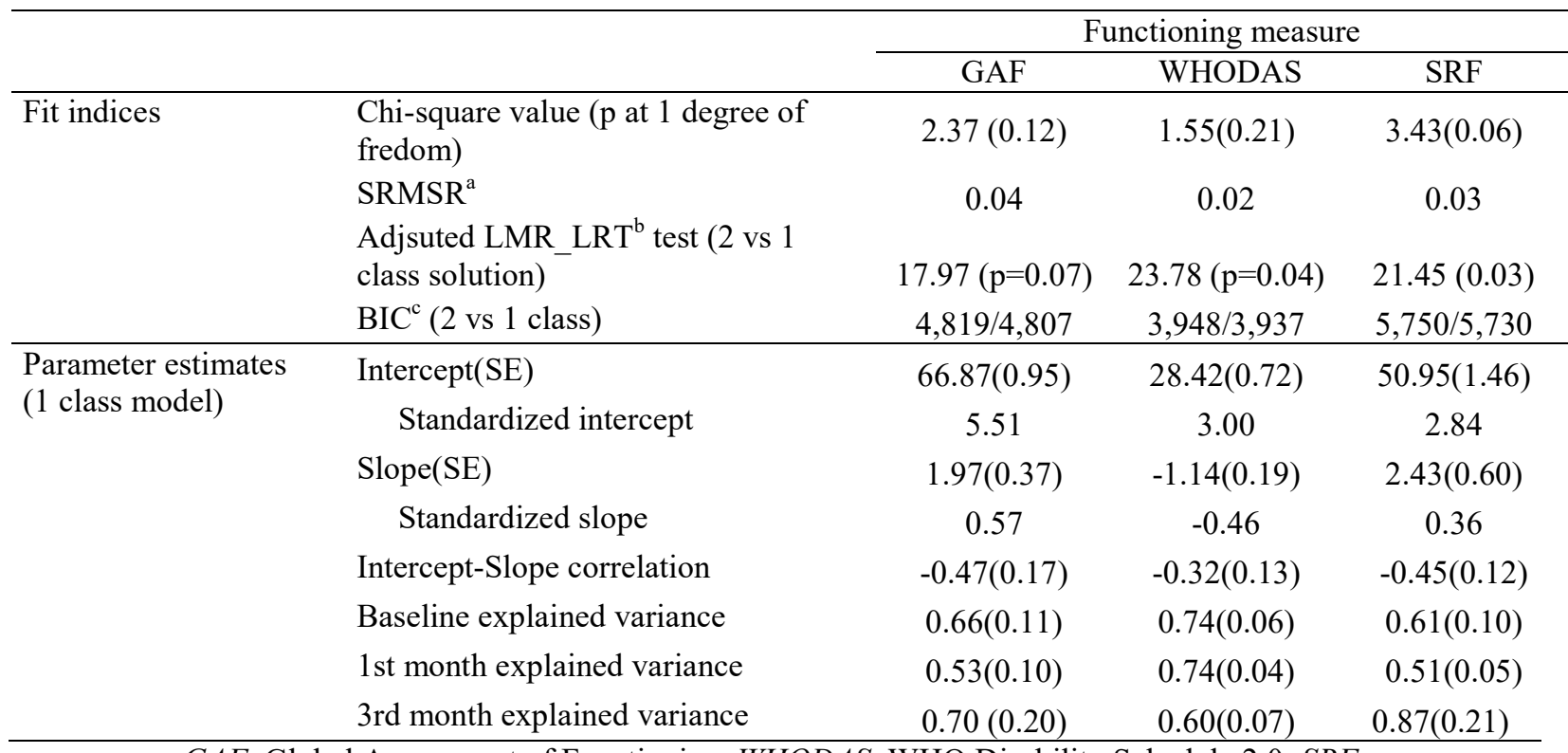

GAF: Global Assessment of Functioning; WHODAS: WHO Disability Schedule 2.0; SRF:

Analogue Scale of Functioning

${ }^{1}$ Standardized Root Mean Square Residual

${ }^{2}$ Adjusted Lo-Mendel Rubin Likelihood Ratio Test (bootstrapped)

${ }^{3}$ Bayesian Information Criterion 
Table 4. Model estimates (SEs), Wald test and parameter Odds Ratios (95\% CIs) and goodness of fit of 12-month MDE status as predicted with GAF, WHODAS, and SRF. Functioning models are added hierarchically to baseline MDE 3-month model. All models adjusted for setting age, sex, health care setting, the presence of mental comorbidities and number of physical comorbidities.

\begin{tabular}{|c|c|c|c|c|c|c|c|c|c|c|}
\hline \multicolumn{2}{|c|}{ Model } & \multirow{2}{*}{$\begin{array}{c}\begin{array}{c}\text { Parameter } \\
\text { Estimate }\end{array} \\
2.42\end{array}$} & \multirow{2}{*}{$\begin{array}{c}\text { Parameter } \\
\text { SE } \\
0.44\end{array}$} & \multirow{2}{*}{$\begin{array}{l}\text { Wald } \\
19.41\end{array}$} & \multirow{2}{*}{$\begin{array}{c}\begin{array}{c}\text { Wald p- } \\
\text { value }\end{array} \\
0.00\end{array}$} & \multirow{2}{*}{$\frac{\mathrm{OR}}{11.19}$} & \multirow{2}{*}{$\begin{array}{c}\text { OR 95\% } \\
\begin{array}{c}\text { Confidence } \\
\text { Interval }\end{array} \\
(4.66-26.92) \\
\end{array}$} & \multirow{2}{*}{$\begin{array}{c}\text { Model } \\
\text { p-value }\end{array}$} & \multirow{2}{*}{$\begin{array}{c}\text { Nagelkerke } \\
\text { Pseudo R2 } \\
0.21\end{array}$} & \multirow{2}{*}{$\begin{array}{c}\text { H-Lb test }(p) \\
--\end{array}$} \\
\hline $\begin{array}{l}\text { Baseline ML } \\
\text { model }\end{array}$ & rd month & & & & & & & & & \\
\hline \multirow[t]{3}{*}{ GAF } & $\mathrm{MDE} \_3 \mathrm{M}$ & 0.46 & 0.67 & 0.26 & 0.61 & 1.59 & $(0.42-5.92)$ & $<0.001 \mathrm{a}$ & 0.57 & $2.12(0.97)$ \\
\hline & I & -0.31 & 0.06 & 19.74 & 0.00 & 0.73 & $(0.65-0.82)$ & & & \\
\hline & $\mathrm{S}$ & -2.01 & 0.36 & 21.31 & 0.00 & 0.14 & $(0.07-0.27)$ & & & \\
\hline \multirow[t]{3}{*}{ WHODAS } & MDE_3M & 1.77 & 0.52 & 6.18 & 0.01 & 5.84 & $(2.08-16.41)$ & $<0.001 \mathrm{a}$ & 0.28 & $6.24(0.62)$ \\
\hline & I & -0.03 & 0.03 & 7.11 & 0.01 & 0.92 & $(0.87-0.98)$ & & & \\
\hline & $\mathrm{S}$ & -0.06 & 0.14 & 0.24 & 0.62 & 0.86 & $(0.65-1.13)$ & & & \\
\hline \multirow[t]{3}{*}{ SRF } & MDE_3M & 0.74 & 0.63 & 0.31 & 0.58 & 2.09 & $(0.60-7.26)$ & $<0.001 \mathrm{a}$ & 0.62 & $5.50(0.70)$ \\
\hline & I & -0.18 & 0.04 & 20.64 & 0.00 & 0.84 & $(0.78-0.90)$ & & & \\
\hline & $\mathrm{S}$ & -0.93 & 0.16 & 24.19 & 0.00 & 0.40 & $(0.29-0.54)$ & & & \\
\hline
\end{tabular}

Multiple imputations used to adjust for within-survey item non-response and lost to follow up

${ }^{a}$ Step significance from MDE baseline model.

${ }^{\mathrm{b}}$ Hosmer-Lemeshow Goodness of fit test 


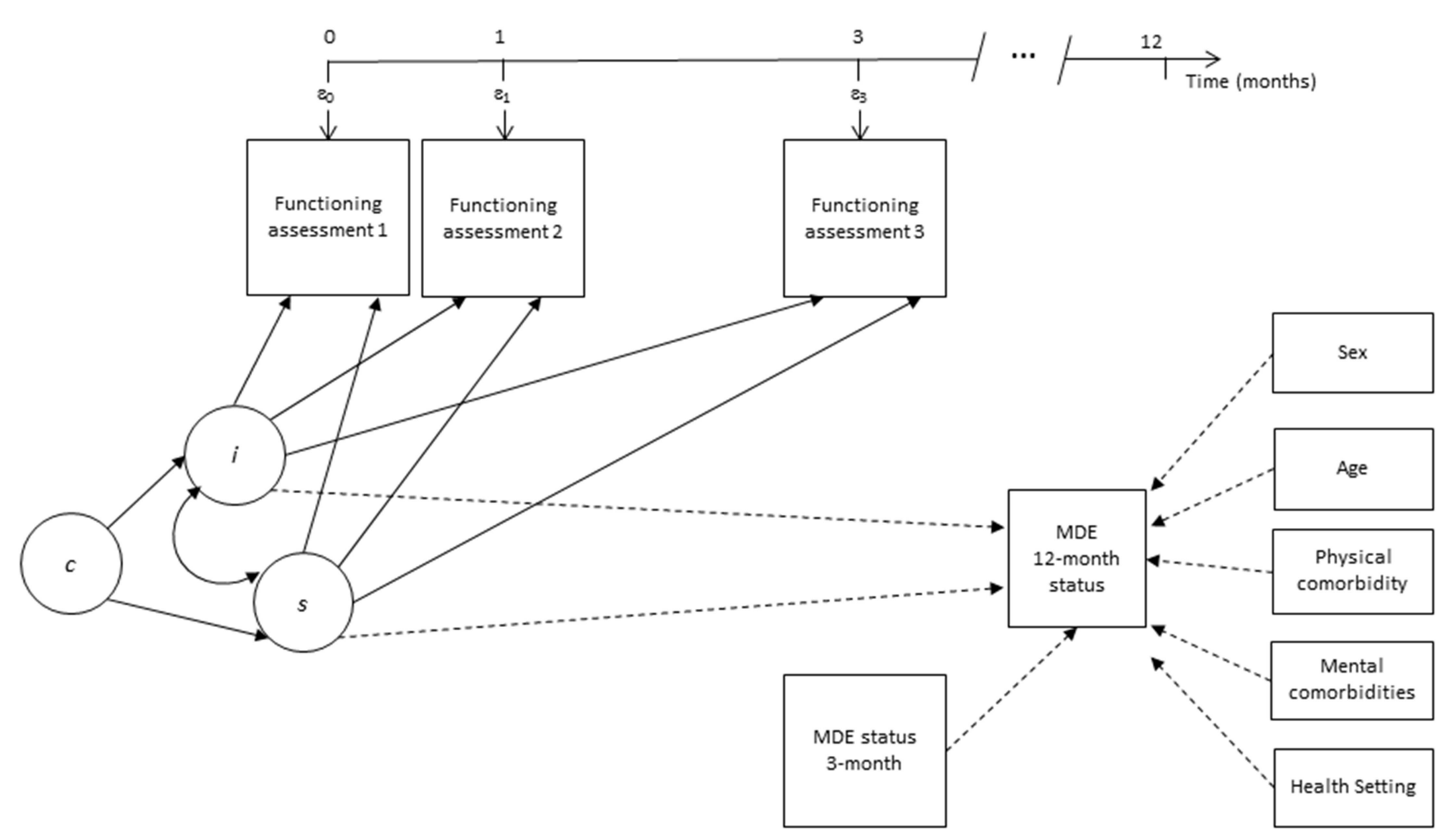

Latent Classes (c); Intercept (i); Slope (s),; error variance (e); MDE: Active Major Depressive Episode

Fig 1 Structural path diagram of the longitudinal Growth Mixture Model (continuous lines) and structural predictive Logistic Regression (dashed lines). Each functioning measure (GAF; WHODAS and SRF) modeled independently 
a) ROC curves for MDE Status at $12^{\text {th }}$ month as predicted by functionality trends

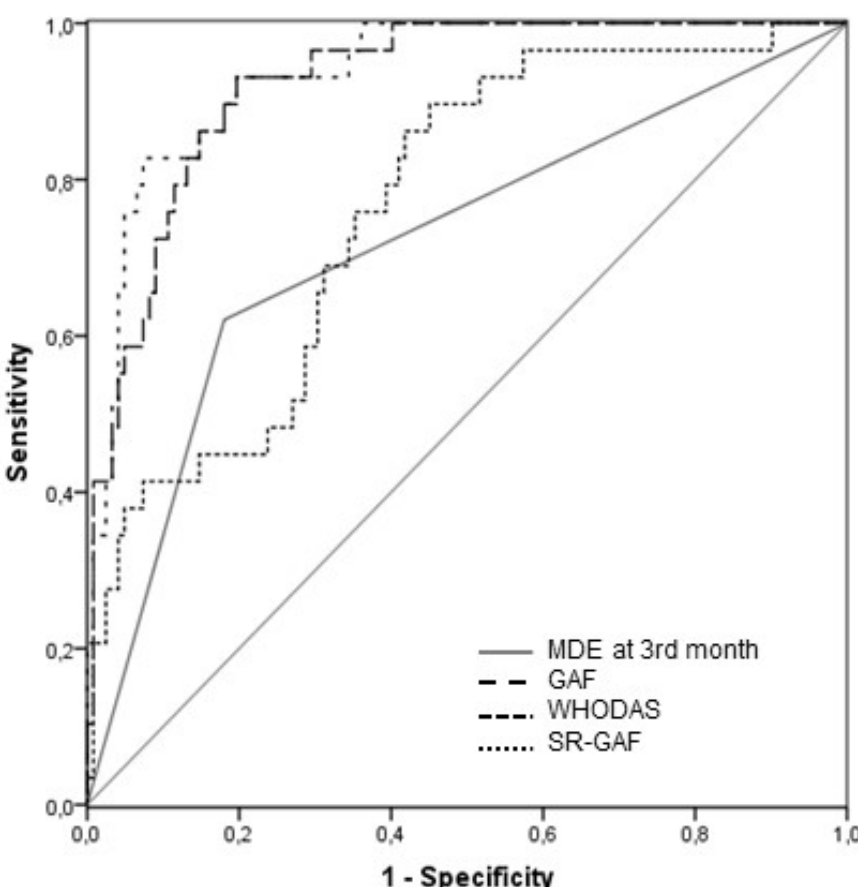

\begin{tabular}{lccc}
\hline & AUC & SE & $95 \% \mathrm{Cl}$ \\
\hline MDE 3rd month only & 0.72 & 0.06 & $0.61-0.83$ \\
GAF & 0.92 & 0.02 & $0.88-0.96$ \\
WHODAS & 0.76 & 0.05 & $0.67-0.85$ \\
SR-GAF & 0.93 & 0.02 & $0.89-0.97$ \\
\hline
\end{tabular}

b) ROC curves for MDE Status at 12th month as

predicted by functionality trends and MDE status at 3rd month

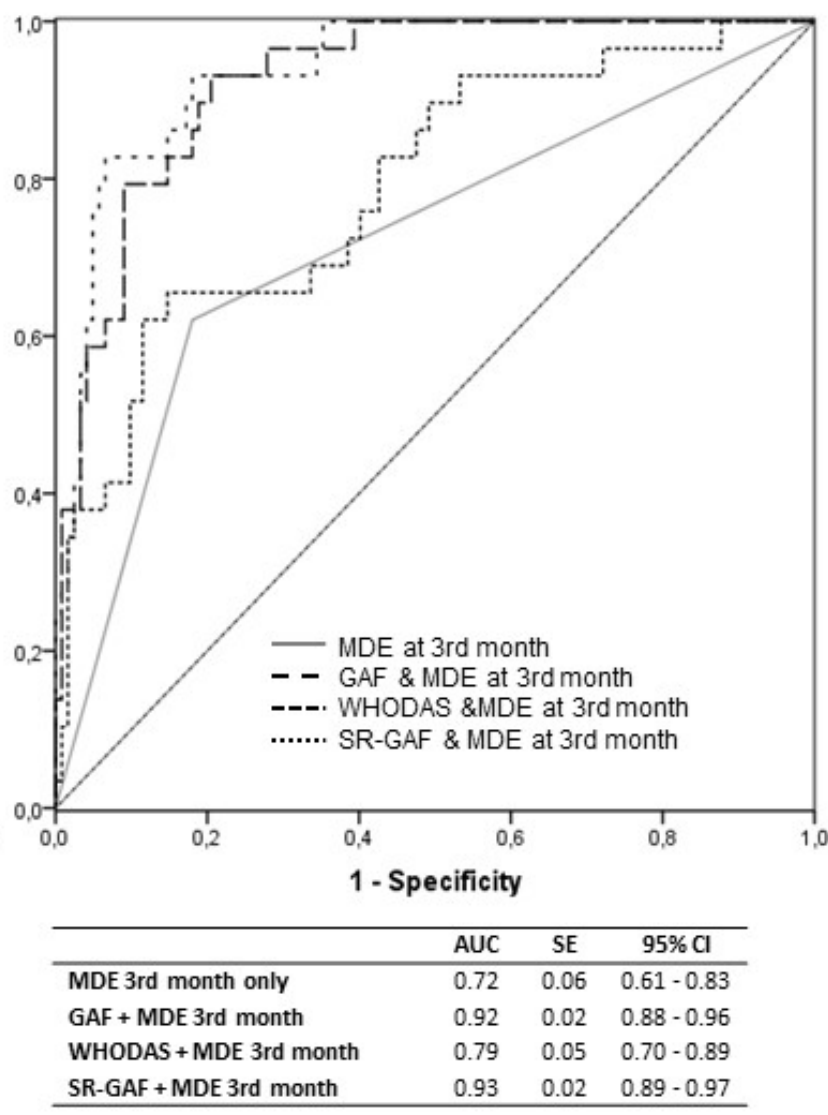

Fig 2. Receiver Operator Curves, Areas Under the Curve (AUC) and SEs of the model estimated probabilities of Major Depression Episode (MDE) status at $12^{\text {th }}$ month, using functioning measures only (a), functioning added to MDE status at third month (b). Predictive MDE status at third month (active/inactive) is shown as a reference. Diagonal represents random prediction 
Table 5. Accuracy values of predictive model scores at the Youden's index: Sensitivity, specificity, positive and negative predictive values and Likelihood ratios and 95\% confidence intervals. Accuracy values of predictive model scores at the Youden's index value: Sensitivity, specificity, positive and negative predictive values and Likelihood ratios and 95\% confidence intervals,

\begin{tabular}{lccc}
\hline & \multicolumn{3}{c}{ Predictive Model } \\
\cline { 2 - 4 } & GAF & WHODAS & SRF \\
\hline Youden's Index & 0.18 & 0.13 & 0.33 \\
Sensitivity & 0.93 & 0.89 & 0.84 \\
Specificity (95\%CI) & $(0.85-0.99)$ & $(0.84-0.95)$ & $(0.73-0.95)$ \\
& 0.83 & 0.56 & 0.95 \\
Positive Predictive Value & $(0.78-0.88)$ & $(0.50-0.63)$ & $(0.92-0.98)$ \\
Negative Predictive Value & 0.61 & 0.86 & 0.78 \\
Likehood Ratio Positive & $(0.50-0.73)$ & $(0.86-0.96)$ & $(0.66-0.90)$ \\
& $(4.86-10.28)$ & $(1.59-2.39)$ & $(8.53-29.34)$ \\
Likehood Ratio Negative & 0.08 & 0.95 & 0.96 \\
& $(0.02-0.24)$ & $(0.11-0.53)$ & $(0.08-0.34)$ \\
\hline
\end{tabular}

Multiple imputations used to adjust for within-survey item non-response and lost to follow up 